\title{
Assessment of Awareness and Knowledge About Package Inserts Amongst Medical Students: A Questionnaire Based Study
}

\author{
Gupta VK ${ }^{1}$,Pathak SS ${ }^{2}$ \\ ${ }^{I}$ (Department of Pharmacology, Jawaharlal Nehru Medical College, Sawangi, Meghe, Wardha, Maharashtra India) \\ ${ }^{2}$ (Department of Pharmacology, Jawaharlal Nehru Medical College, Sawangi, Meghe, Wardha, Maharashtra India)
}

\begin{abstract}
A package insert or prescribing information (in Europe, Patient information leaflet for human medicines or Package Leaflet for veterinary medicines) is a document provided along with a prescription medication to provide additional information about that drug. In developing countries, the package insert is considered an important source of drug information for health care providers as well, because of limited ability to access up-to-date information about drugs. The quality and quantity of information available in the package insert has been shown to influence patient's compliance and satisfaction.
\end{abstract}

This study was undertaken to assess the knowledge about package inserts amongst medical students.

A prevalidated questionnaire based study was conducted amongst 100 medical students. It was observed that significantly large number of student (42\%) do not even read package inserts. $18 \%$ looked for indications, $19 \%$ looked for contraindications, $21 \%$ looked for adverse effects and $23 \%$ opinioned that it should be in mother tongue. It is a good idea to review the need of more awareness amongst the students and certain changes in the package inserts.

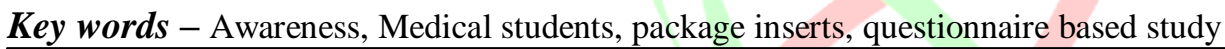

\section{Introduction}

The patient package insert (PPI) is important for providing essential drug information for patients taking over-the-counter as well as prescription-only medications. In developing countries, the PPI is considered an important source of drug information for health-care providers as well, because of a limited ability to access up-to-date information about drugs. In addition, studies have shown that the PPI helps bridge the information gap between health care providers and patients and enhances patients' knowledge about medications $[\underline{1}, \underline{2}]$. The quality and quantity of information available in the PPI has been shown to influence patients' compliance and satisfaction $[\underline{3}, \underline{4}]$. There are also indications that patients who read the PPI are more likely to follow the instructions, especially if the information in the PPI agrees with the instructions of the physician and/or pharmacist [5]. A study carried out in Denmark found that patients may be confused by inconsistent information in PPI, which leads to reduced compliance [6].

The design and the amount of information in the PPI are usually regulated by the legislative health authorities.

In India the concept of package insert is governed by the 'Drugs and Cosmetic Act (1940) and Rules (1945)' [3]. Section D (II) of the Rules lists the headings according to which information should be provided in the package inserts. 'Section6.2' mandates that the package insert must be in 'English and must include information on therapeutic indications, posology and method of administration, contraindications, special warnings and precautions, drug interactions, contraindications in pregnancy and lactation, effects on ability to drive and use machines, undesirable effects, and antidote for overdosing. 'Section 6.3' mandates pharmaceutical information on list of excipients, incompatibilities, shelf life as packaged, after dilution or reconstitution, or after first opening the container, special precautions for storage, nature and specification of container, and instruction for use/ handling. It is not mentioned clearly, whether the package inserts are directed only at the physicians or at the patients as well. [7]

The present study was undertaken to assess the awareness and knowledge about package inserts amongst medical students. 


\section{Materials and Methods}

A questionnaire focusing on expectations and preferences of patients regarding package inserts was distributed to the 100 medical students. The questionnaire consisted specific questions regarding knowledge about package inserts and opinion about whether they are helpful or not.

\section{Results}

The majority ( $42 \%$ of all medical students) said that they never read the package inserts. Out of $58 \%$ who read the package inserts, $21 \%$ looked for adverse effects, $19 \%$ looked for contraindications and 18\% looked for indications. 23\% opinioned that it should be in mother tongue. (Multiple answers were possible)

TABLLE- Selected Comments About Package Inserts By 100 Participants (Multiple Answers Were Possible)

\begin{tabular}{|c|c|c|c|c|c|}
\hline & $\begin{array}{c}\text { Never read the } \\
\text { package inserts }\end{array}$ & $\begin{array}{c}\text { Looked for } \\
\text { Adverse effect }\end{array}$ & $\begin{array}{c}\text { Looked for } \\
\text { contraindication }\end{array}$ & $\begin{array}{c}\text { Looked for } \\
\text { indications }\end{array}$ & $\begin{array}{c}\text { Should be in } \\
\text { mother tongue }\end{array}$ \\
\hline No. of Students & 42 & $21(9)$ & $19(7)$ & $18(7)$ & 23 \\
\hline
\end{tabular}

(No. in bracket shows no. of students who opinioned that Package inserts should be in mother tongue)

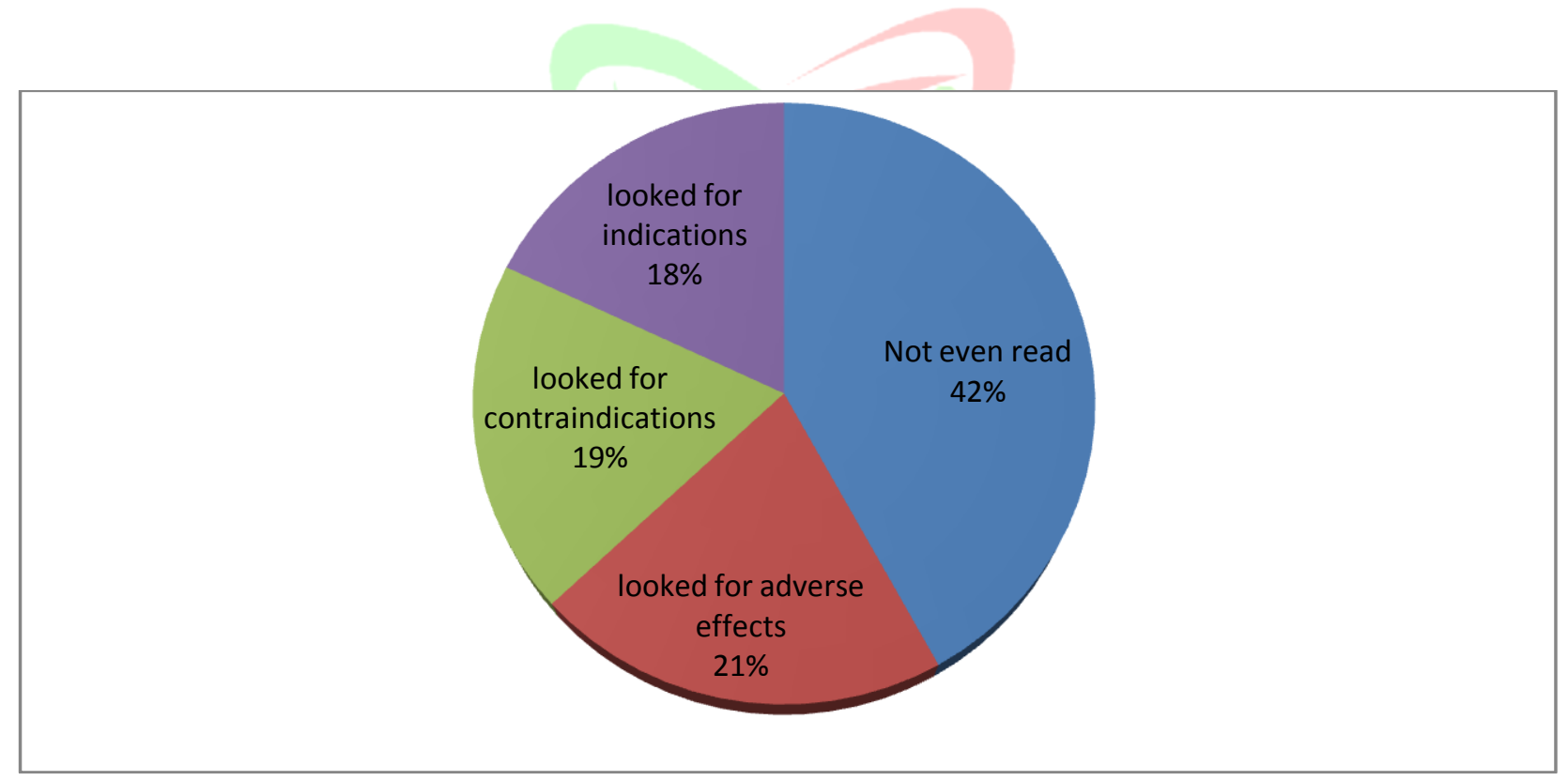

Fig. - selected comments about package inserts by 100 participants (multiple answers were possible)

\section{DISCUSSIONS}

The result of the study depicted many problems associated with package inserts. As package inserts are one of the most frequently used sources of written drug information, approaches to optimize them should be explored as soon as possible. This especially refers to difficulties in understanding the extensive information provided, and suggests a more suitable structure of package inserts. Package inserts should contain only the information that is of paramount importance for the patient, although this is debatable from a legal point of view. The address of manufacturer is currently mentioned on package inserts, which can take up to $25 \%$ of the space available, and this might have to be reconsidered. 


\section{CONCLUSION}

The package insert is a good source of information in addition to instructions your doctor may give you. It's a good idea to review the package insert for any new medicine you take and to look at it again if anything about your health changes but there is a need of more awareness amongst the population and certain changes in the package insert.

\section{REFERANCES}

[1]. Regner MJ, Hermann F, Ried LD. Effectiveness of a printed leaflet for enabling patients to use digoxin side-effect information. Drug Intell Clin Pharm. 1987;21(2):200-4.

[2]. Mottram DR, Reed C. Comparative evaluation of patient information leaflets by pharmacists, doctors and the general public. J Clin Pharm Ther. 1997;22(2):127-34.

[3]. Gibbs S, Waters WE, George CF. Prescription information leaflets: a national survey. $J$ R Soc Med. 1990;83(5):292-97.

[4]. Gibbs S, Waters WE, George CF. The benefits of prescription information leaflets. Br J Clin Pharmacol. 1989;27(6):723-39.

[5]. Weitbrecht WU, Vosskamper C. Influence of the drug package information paper on compliance of neurological and psychiatric outpatients. Fortschr Neurol Psychiatr. 2000;70(4):178-84.

[6]. Bjerrum L, Foged A. Patient information leaflets--helpful guidance or a source of confusion? Pharmacoepidemiol Drug Saf. 2003;12(1):55-59.

[7]. YM Shivalkar, JPGM 2009; 55 (2) : 104-107. 